\title{
Facilitation of taste memory acquisition by experiencing previous novel taste is protein-synthesis dependent
}

\author{
Maayan Merhav and Kobi Rosenblum ${ }^{1}$ \\ Department of Neurobiology and Ethology, Faculty for Science, Haifa University, Haifa 30905, Israel
}

\begin{abstract}
Very little is known about the biological and molecular mechanisms that determine the effect of previous experience on implicit learning tasks. In the present study, we first defined weak and strong taste inputs according to measurements in the behavioral paradigm known as latent inhibition of conditioned taste aversion. We then demonstrated that a strong novel taste input facilitated acquisition of the memory of subsequent weak taste input in inverse correlation with the time interval between the inputs. However, not only was a strong taste input unable to rescue an immediately subsequent strong taste input when the gustatory cortex was under the influence of the protein-synthesis inhibitor, anisomycin, but the effect of the interaction was to reduce the variation among individual taste memories. Taken together, these results demonstrate that taste memory facilitation, induced by previously experiencing a different unimodal taste input, depended on time, novelty, and directionality. Moreover, the results imply that learning is enhanced on the level of acquisition but not of molecular consolidation.
\end{abstract}

Previously learned knowledge or skill may affect the way new knowledge or skill is acquired or performed. These interactions between experiences can be positive or negative, and were studied extensively in connection with education, psychology, and motor learning, but very little is known about the relevant neuronal substrates (Seidler 2007). From a temporal perspective, learning can be divided into an immediate "on-line" acquisition phase and an "off-line" consolidation phase (Balas et al. 2007). The consolidation phase itself comprises two different phenomena: (1) molecular consolidation, that is protein-synthesis dependent in a time frame of hours, and (2) system consolidation, which refers to the transformation of the memory from hippocampus dependent to independent, in a time scale of weeks to years (Dudai 2004). Acquisition, as well as both forms of consolidation, can be affected by previous experiences. However, it is not clear at which stage of learning the previous experience affects the ability to learn new information.

In conditioned taste aversion (CTA) an organism learns to associate between tastes and to avoid it if it was associated with malaise (Bures et al. 1998). In latent inhibition (LI) of CTA, animals are introduced to the novel taste a few days before the CTA, and this pre-exposure weakens their aversion to the taste, compared with that which follows CTA alone (Revusky and Bedarf 1967; De la Casa and Lubow 2002). The weakening of the aversion indicates that the taste was learned, became familiar, and consolidated after or during the pre-exposure, and that this resulted in reduction of the strength of the CTA to the same taste. Therefore, one can measure the formation of a memory of a novel taste input per se by using the LI paradigm (Rosenblum et al. 1993, 1995, 1996; Gallo et al. 1998). Taste-memory consolidation is dependent on functional protein-synthesis machinery in the gustatory cortex (GC), and this machinery resides within the insular cortex (Rosenblum et al. 1993; Houpt and Berlin 1999). Clear modulation of the translational machinery was detected following consumption of a novel taste (Belelovsky et al. 2005; Yefet et al. 2006). Moreover, various proteins that are

\footnotetext{
1Corresponding author.
}

E-mail kobir@psy.haifa.ac.il; fax 972-4-8249654.

Article is online at http://www.learnmem.org/cgi/doi/10.1101//m.986008. known to regulate protein synthesis were found to play major roles in taste memory consolidation (Banko et al. 2005, 2006; Costa-Mattioli et al. 2007).

In a previous study, we found that unimodal taste sensory information can attenuate or block the formation of a previously learned taste (Merhav et al. 2006). In the present study we tested the ability of a strong taste input to convert an immediately subsequent, different, weak taste input, to a strong input. Since the GC is necessary for both learning and retrieval of taste (Bures et al. 1998), we tested the possibility for a strong taste input under the influence of protein inhibition in the GC, to be rescued and remembered if another strong taste input had been learned previously.

\section{Results}

Consumption of a small amount of taste did not produce a detectable memory in the LI paradigm According to the latent inhibition (LI) paradigm, a pre-exposure to a novel taste, before induction of CTA to the same taste, results in attenuation of the CTA (Revusky and Bedarf 1967). Therefore, one can measure the formation of novel taste memory per se by using the LI paradigm. In order to measure the effect of a specific amount (in milliliters) of a given taste on the formation of longterm taste memory, rats were subjected to LI of CTA (Fig. 1A). Different groups of rats were pre-exposed to zero (i.e., CTA), 5, 10, or $15 \mathrm{~mL}$ of $0.1 \%$ saccharin or of $0.3 \% \mathrm{NaCl}$. The pre-exposures took place $3 \mathrm{~d}$ before conditioning to the same taste, and the test for taste preference was carried out $2 \mathrm{~d}$ after the conditioning.

Consumption of 10 or more milliliters of saccharin resulted in weaker aversion than that under CTA $(P<0.001$ in both groups) and produced a detectable memory trace (Rosenblum et al. 1996; Belelovsky et al. 2005). In contrast, pre-exposure to 5 $\mathrm{mL}$ of saccharin did not produce a detectable memory, and the animals' response was not different from that of the CTA group $(P=0.198$; Fig. 1A).

The same protocol was used to determine the subthreshold value for $\mathrm{NaCl}$ pre-exposure, i.e., $\mathrm{LI}$ with $\mathrm{NaCl}$. As in the case of saccharin, both 10 and $15 \mathrm{~mL}$ of $\mathrm{NaCl}$ induced a detectable long- 
A

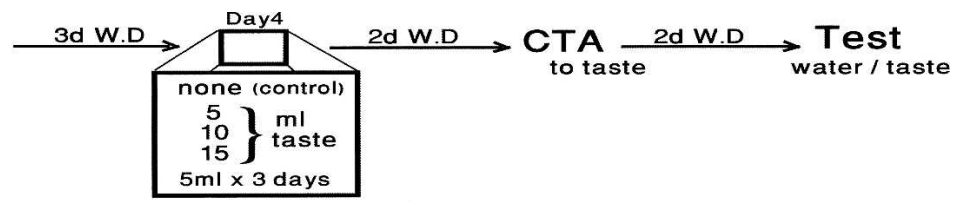

B

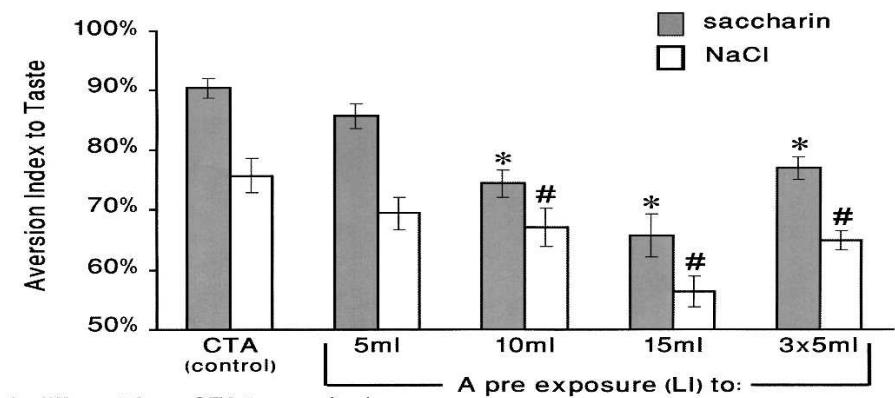

* different from CTA to saccharin

\# different from CTA to $\mathrm{NaCl}$

Figure 1. Definition of subthreshold amount of taste input, to produce memory trace, in latent inhibition (LI) paradigm. (A) Groups of rats were subjected to a LI protocol: Different groups were pre-exposed either to $0 \mathrm{~mL}$ (i.e., CTA) or to 5,10 , or $15 \mathrm{~mL}$ of taste $(0.1 \%$ saccharin or $0.3 \% \mathrm{NaCl})$. An additional group was pre-exposed to three 5-mL doses of taste, at 24-h intervals. Aversion conditioning to the taste and a choice test were administered on the following days. (B) Among the saccharin groups: A pre-exposure to $5 \mathrm{~mL}(85.66 \pm 2.1 \%, n=8)$ did not reduce the aversion compared with that in the CTA group $(90.42 \pm 1.73 \%, n=13, P=0.198)$. Pre-exposures to 10 or $15 \mathrm{~mL}$ produced a clear reduction in the aversion level $(74.36 \pm 2.26 \% n=16$ and $65.68 \pm 3.59 \% n=8$, respectively), compared with that in the CTA group $(P<0.001$ in both groups). Three pre-exposures to $5 \mathrm{~mL}$ elicited a reduction in the aversion level $(76.92 \pm 1.85 \% n=8)$ compared with that in the CTA group $(P=0.001)$. Among the $\mathrm{NaCl}$ groups: Pre-exposures to 10 or $15 \mathrm{~mL}$ of $\mathrm{NaCl}$ reduced the aversion level $(67.12 \pm 3.20 \% n=10,56.32 \pm 2.54 \% n=12$, respectively) compared with that in the CTA group $(75.62 \pm 2.89 \% n=11, P=0.028$ and $P<0.001$, respectively). However, a pre-exposure to $5 \mathrm{~mL}$ did not reduce the aversion compared with that in the CTA group $(69.4 \pm 2.8 \% n=10$, $P=0.102$ ). Three pre-exposures to $5 \mathrm{~mL}$ did induce a reduction in the aversion level compared with that in the CTA group $(64.91 \pm 1.56 \% n=12, P=0.004)$

term memory in the LI paradigm, which was manifested as weaker aversion than that in the CTA group $(P=0.028, P<0.001$, respectively). Pre-exposure to $5 \mathrm{~mL}$ of $\mathrm{NaCl}$ was not sufficient to produce a detectable memory: It did not result in weaker aversion than that of CTA $(P=0.102)$. In light of these results, we defined a strong taste input, needed to produce LTM, as $10 \mathrm{~mL}$ or more, and a weak taste input that was insufficient to produce long-term memory (LTM) as $5 \mathrm{~mL}$, and these criteria applied to both tastes. These results suggest that the strength of a taste memory is proportional to the amount of the taste consumed at pre-exposure or at the time of incidental learning.

One main parameter that was tested in the experiment above is the amount of taste input at the pre-exposure. Another variable can be the number of pre-exposures. Indeed, we observed a tendency for weaker aversion in animals that were preexposed to $5 \mathrm{~mL}$ of novel taste. We therefore further investigated whether three episodes of pre-exposure to $5 \mathrm{~mL}$ of a given taste, $24 \mathrm{~h}$ apart, would induce a detectable memory trace (Fig. 1A). The results obtained (Fig. 1B) demonstrate that, whereas a single exposure to $5 \mathrm{~mL}$ of saccharin did not induce a detectable memory, three such exposures, to either saccharin or $\mathrm{NaCl}$, did induce a memory: Three pre-exposures to $5 \mathrm{~mL}$ of saccharin or $\mathrm{NaCl}$ resulted in weaker aversion than CTA to saccharin or $\mathrm{NaCl}$, respectively ( $P=0.001$ and $P=0.004$, respectively).

Facilitation of a weak taste input by previous consumption of a different strong taste input

In light of the definition of weak and strong taste inputs, with respect to their ability to produce detectable memory in the LI paradigm, we hypothesized that a strong input of one taste would facilitate formation of a memory of another taste. There- fore, at $0.5 \mathrm{~h}$ before their exposure to the weak input of $5 \mathrm{~mL}$ of saccharin (Fig. 2A), the test rats consumed $10 \mathrm{~mL}$ of $\mathrm{NaCl}$, i.e., a strong input, and a control group consumed $10 \mathrm{~mL}$ of tap water. Both groups underwent conditioning procedures as described above and $3 \mathrm{~d}$ after CTA were subjected to a multiple-choice test between saccharin and water (Fig. 2A).

The results show (Fig. 2B, third bar from left) that consuming $10 \mathrm{~mL}$ of $\mathrm{NaCl} 0.5 \mathrm{~h}$ before the pre-exposure to 5 $\mathrm{mL}$ of saccharin resulted in a lower aversion to saccharin than that in either the CTA or the control group $(P<0.001$, $P=0.001$, respectively), which shows that $10 \mathrm{~mL}$ of $\mathrm{NaCl}$ facilitated memory formation with respect to $5 \mathrm{~mL}$ of saccharin (i.e., enhanced incidental learning and reduced CTA in the LI paradigm). In contrast, consumption of $10 \mathrm{~mL}$ of tap water $0.5 \mathrm{~h}$ before the pre-exposure to $5 \mathrm{~mL}$ of saccharin (Fig. 2B, second bar from left) produced an aversion similar to that in the CTA group $(P=0.389)$. These results show that a weak input could be facilitated into strong memory if it was preceded by another strong taste input. We concluded that, although 5 $\mathrm{mL}$ was a weak input with respect to producing a detectable effect in the LI paradigm, some memory was retained following one exposure to $5 \mathrm{~mL}$; therefore, weak and strong inputs are relative terms, since three weak pre-exposures did induce long-term memory. Moreover, the results suggest that "weak" does not mean necessarily short-term memory and "strong" does not mean necessarily long-term memory: Several exposures to a weak input produce clear long-term memory.

\section{Effect of time interval between the strong and weak inputs on facilitation of the weak taste input}

As shown above, under the LI paradigm, $10 \mathrm{~mL}$ of $\mathrm{NaCl}$ facilitated memory formation with respect to $5 \mathrm{~mL}$ of saccharin. We wished to determine whether the facilitation of the weak input was a function of the time interval between the strong (i.e., 10 $\mathrm{mL} \mathrm{NaCl}$ ) and the weak (i.e., $5 \mathrm{~mL}$ saccharin) inputs. To that end, two groups of rats were pre-exposed to $5 \mathrm{~mL}$ of saccharin according to the LI paradigm (Fig. 2A), but 5 or $8 \mathrm{~h}$ prior to this preexposure the rats had consumed $10 \mathrm{~mL}$ of $\mathrm{NaCl}$. Three days later all groups were conditioned to saccharin, and on the test day they were subjected to the multiple-choice test between water and saccharin, as described above.

Rats that consumed $10 \mathrm{~mL} \mathrm{NaCl} 5 \mathrm{~h}$ prior to their preexposure to $5 \mathrm{~mL}$ of saccharin (Fig. 2B, second bar from right) exhibited a significantly stronger memory trace with respect to saccharin than those in the CTA group $(P=0.028)$, but not than those in the control group $(P=0.206)$, which had been exposed to $10 \mathrm{~mL}$ of water $0.5 \mathrm{~h}$ prior to their pre-exposure to $5 \mathrm{~mL}$ of saccharin. In contrast to the results obtained after the 0.5- and 5 -h time intervals, consumption of $10 \mathrm{~mL}$ of $\mathrm{NaCl} 8 \mathrm{~h}$ before the pre-exposure to $5 \mathrm{~mL}$ of saccharin (Fig. 2B, first bar on right) did not facilitate memory formation with respect to the weak input of saccharin. The rats in the 8-h interval group exhibited a similar 
A

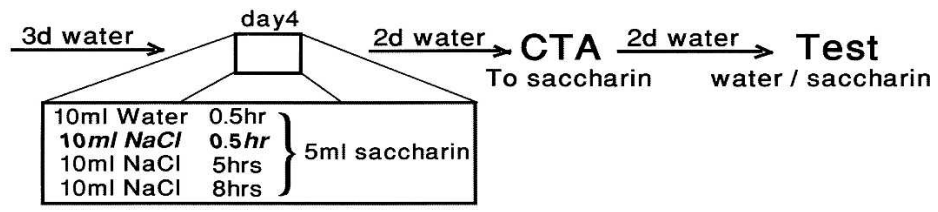

B

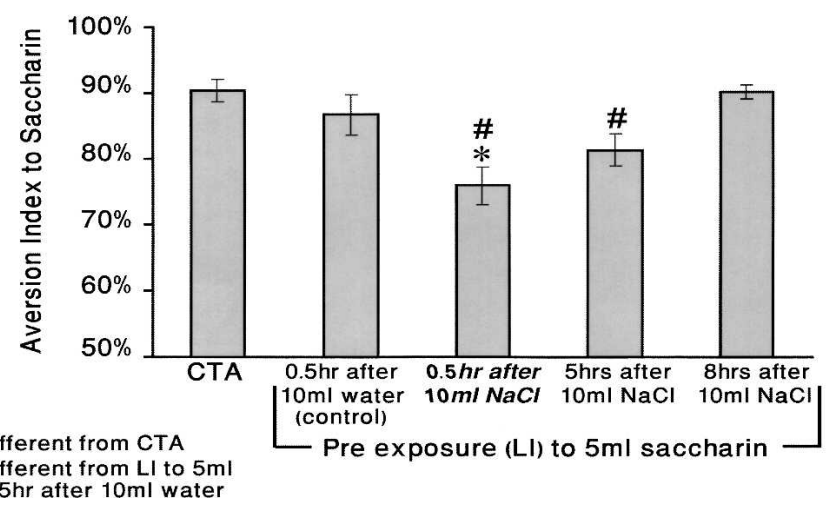

Figure 2. A strong taste input stabilized memory formation with respect to a subsequent weak taste input. (A) Four groups were pre-exposed to $5 \mathrm{~mL}$ of saccharin under the LI paradigm. On day 4 , at 0.5 , 5 or $8 \mathrm{~h}$ prior to the pre-exposure to $5 \mathrm{~mL}$ of saccharin, three groups of rats consumed $10 \mathrm{~mL}$ of NaCl . The fourth group (control) consumed $10 \mathrm{~mL}$ of tap water at $0.5 \mathrm{~h}$ prior to consumption of $5 \mathrm{~mL}$ of saccharin. (B) The saccharin aversion index in rats that consumed $10 \mathrm{~mL}$ of $\mathrm{NaCl} 0.5 \mathrm{~h}$ before their pre-exposure to $5 \mathrm{~mL}$ of saccharin was lower $(75.92 \pm 2.88 \% n=21)$ than in those under CTA $(90.42 \pm 1.73 \% n=13, P<0.001)$ or in the control group $(86.76 \pm 3.07 \% n=10, P=0.001)$. The rats that consumed $10 \mathrm{~mL}$ of $\mathrm{NaCl} 5 \mathrm{~h}$ prior to their pre-exposure to $5 \mathrm{~mL}$ of saccharin had a significantly $(P=0.028)$ lower aversion index $(81.37 \pm 2.49 \%, n=12)$ than those in the CTA group but not significantly $(P=0.206)$ different from those in the control group. The rats that consumed 10 $\mathrm{mL}$ of $\mathrm{NaCl} 8 \mathrm{~h}$ before pre-exposure to $5 \mathrm{~mL}$ of saccharin exhibited a similar aversion to those in the CTA group $\left(90.21 \pm 1.02 \% n=8, P=0.963\right.$; ANOVA: $\left.F_{(4,58)}=5.915, P<0.001\right)$.

aversion to that of the ones in the CTA group $(P=0.963)$ and in the control group $(P=0.464)$. These experiments demonstrated that, when followed by an interval of $0.5-5.0 \mathrm{~h}$, the strong taste input facilitated memory formation with respect to the weak input, whereas, when followed by an 8-h interval, it did not. In addition, the facilitation of the weak input was inversely correlated with the time interval between the strong and the weak inputs (ANOVA: $\left.F_{(4,58)}=5.915, P<0.001\right)$.

Taste memory can be enhanced by another novel, but not familiar, taste input

Taste novelty is a critical parameter in the behavioral, electrophysiological, and biochemical correlates of taste learning (Bahar et al. 2004; Belelovsky et al. 2005; Merhav et al. 2006). In the present study we aimed to determine how the novelty factor of the reinforcing taste would affect its ability to facilitate the weak, 5-mL saccharin input: We therefore supplied the rats with $\mathrm{NaCl}$ during six consecutive days, prior to the "pre-exposure" day (Fig. 3A).

The results show (Fig. 3B) that familiarization with the taste of $\mathrm{NaCl}$ eliminated its ability to facilitate memory formation with respect to the 5 -mL saccharin input. The rats that had received $\mathrm{NaCl}$ during $6 \mathrm{~d}$ prior to preexposure showed stronger aversion than

A

B those to which $\mathrm{NaCl}$ was a novel taste $(P=0.025)$, in fact, similar to that among the control group (Fig. 2B; $P=0.948$ ). According to this result, we conclude that supplying the rats with a familiar taste had a similar effect to supplying them with water (ANOVA: $F_{(2,36)}=3.958$, $P>0.03)$.

\section{Attenuation of taste-memory consolidation by application of the protein-synthesis inhibitor anisomycin to the gustatory cortex We aimed to test whether the potenti- ated effect described above was due to reinforcement of acquisition or to mo- lecular consolidation. Therefore, we tested whether a strong input would rescue the consolidation of a different strong input, which had been given under the influ- ence of the protein synthesis inhibitor, anisomycin. It was shown previously that local application of the protein- synthesis inhibitor anisomycin to the GC before consumption of a novel taste attenuated long- but not short-term taste memory (Rosenblum et al. 1993; Houpt and Berlin 1999). It is thus ac- cepted that taste information acquisi- tion is independent of protein synthe- sis, whereas the subsequent consolida- tion process is dependent on functional protein synthesis in the GC.}

In order to test the ability of novel taste learning to rescue the memory of subsequent taste learning when protein synthesis in the GC is blocked, we first had to determine the time frame within which anisomycin acts in the GC to affect taste learning. We thus wanted to define a time frame of taste administration such that anisomycin clearly would affect the second but not the first taste.
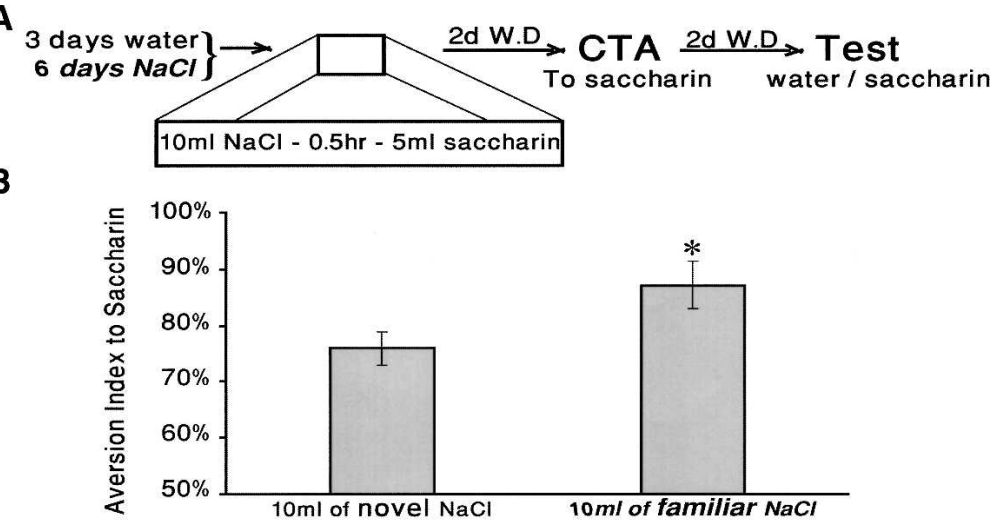

$\mathrm{LI}$ to $5 \mathrm{ml}$ saccharin, given $0.5 \mathrm{hr}$ after...

*higher than novel $\mathrm{NaCl}$

Figure 3. A familiar taste does not stabilize memory formation with respect to a subsequent weak input. $(A)$ Rats consumed $10 \mathrm{~mL}$ of $\mathrm{NaCl} 0.5 \mathrm{~h}$ prior to consumption of $5 \mathrm{~mL}$ saccharin under the $\mathrm{LI}$ paradigm. $\mathrm{NaCl}$ was a novel taste to the control group, but familiar to the experimental group, which had been introduced to $\mathrm{NaCl}$, during six previous drinking sessions. (B) The familiar $\mathrm{NaCl}$ taste did not facilitate memory formation with respect to the weak input of saccharin, whereas the novel $\mathrm{NaCl}$ taste did. The aversion obtained in the "familiar $\mathrm{NaCl}^{\prime}$ group was $87.14 \pm 4.20 \%(n=8)$, which was similar to that of the "5 mL of saccharin after $10 \mathrm{~mL}$ of water" (control) group $(P=0.948)$ and higher than that of the "novel NaCl" group $\left(P=0.025\right.$; ANOVA: $\left.F_{(2,36)}=3.958, P=0.028\right)$. 
A

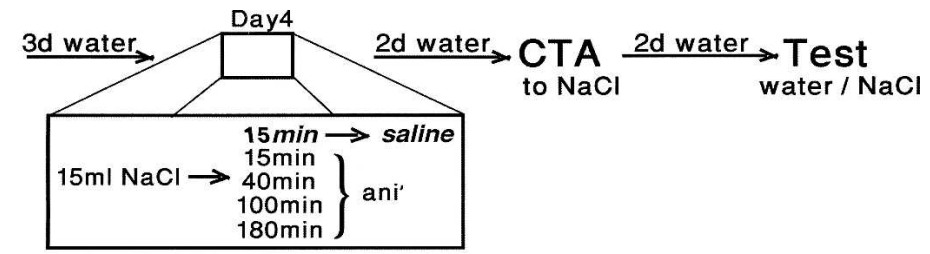

B

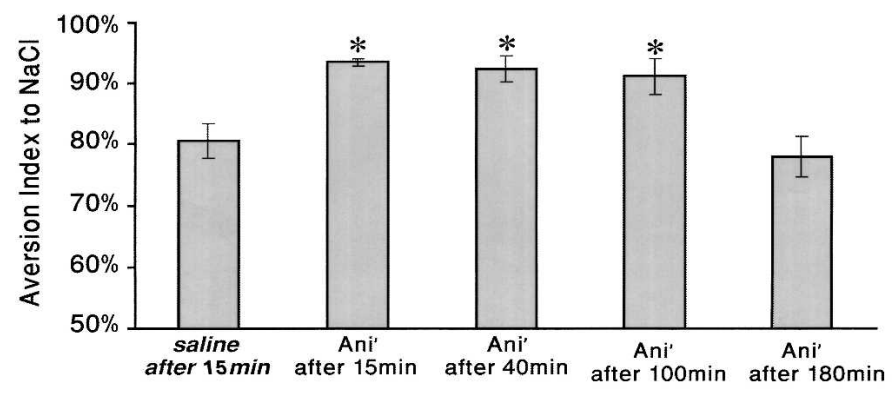

Pre exposure (LI) to $15 \mathrm{mI} \mathrm{NaCl}$

*

higher than the Saline and the Ani $180^{\prime}$ groups

Figure 4. Formation of taste memory remained sensitive to protein-synthesis inhibition for $>100 \mathrm{~min}$ and $<180$ min following consumption of the taste. (A) Groups consumed $15 \mathrm{~mL}$ of $\mathrm{NaCl}$ under the $\mathrm{LI}$ paradigm. Then, at four different time points $(15,40,100$, or 180 min after the pre-exposure), anisomycin was microinjected bilaterally into the GC. The rats in the control group were microinjected with saline at the 15-min time point. (B) Rats that were microinjected with anisomycin at 15,40, or 100 min after pre-exposure to $15 \mathrm{~mL}$ of $\mathrm{NaCl}$ exhibited aversion indexes of $93.53 \pm 0.535 \% n=10$, $92.38 \pm 2.072 \% n=7$, and $91.11 \pm 3.05 \% n=8$, respectively, which were higher than that of the saline group $(80.52 \pm 2.77 \% n=11, P<0.001, P=0.002, P=0.003$, respectively). However, the rats which received anisomycin $180 \mathrm{~min}$ after pre-exposure to $\mathrm{NaCl}$ exhibited an aversion index of $77.91 \pm 3.29 \% n=7$, which was similar to that of the saline group $(P=0.466)$ and lower than those of the 15-, 40- and 100-min groups $(P<0.001, P=0.001, P=0.001$, respectively; ANOVA: $\left.F_{(4,38)}=8.437, P=0.000\right)$. Levene's test for equality of variances revealed that the variance of the 15 -min group was lower than those of the 40 - and 100-min groups $(P<0.05)$.

Toward that end, rats in five groups were each implanted with two guiding cannulae, positioned bilaterally above the GC. After more than a week of recovery, all groups were pre-exposed to $15 \mathrm{~mL}$ of $\mathrm{NaCl}$ in accordance with the LI paradigm (Fig. 4A). On the pre-exposure day (day 4), 15 min after their consumption of $15 \mathrm{~mL}$ of $\mathrm{NaCl}$, the rats of the control group were injected with saline (a vehicle), bilaterally to the insular cortices. The other four groups were injected with anisomycin (see Materials and Methods) $15,40,100$, or $180 \mathrm{~min}$ after the $\mathrm{NaCl}$ pre-exposure. On the subsequent days, the rats were conditioned to $\mathrm{NaCl}$ and subjected to the choice test between $\mathrm{NaCl}$ and water (Fig. 4A).

The results show that microinjection of anisomycin ( $\mathrm{ani}^{\prime}$ ) to the taste cortex was effective in preventing taste memory consolidation, even when administered 100 min after taste consumption (Fig. 4B). No memory traces for the $\mathrm{NaCl}$ pre-exposure were detected among the 15-, 40-, or 100-min ani' groups: The aversion indices of these groups were all higher than that of the saline group $(P<0.001, P=0.002$, and $P=0.003$, respectively). Application of Levene's test for equality of variances revealed that the variance of the taste $\rightarrow 15^{\prime} \rightarrow$ Ani' $^{\prime}$ group was significantly lower than those of the taste $\rightarrow 40^{\prime} \rightarrow$ Ani' $^{\prime}$ and the taste $\rightarrow 100^{\prime} \rightarrow$ Ani' $^{\prime}$ groups $(P<0.05)$. This suggests that the effect of anisomycin was cleaner when it was applied $15 \mathrm{~min}$ after the consumption of taste.

In contrast to its effect at 15,40 , or $100 \mathrm{~min}$ after the consumption of $15 \mathrm{~mL}$ of $\mathrm{NaCl}$, application of anisomycin after 180 min had no effect on memory consolidation. A memory trace for the $15-\mathrm{mL}$ pre-exposure was fully detected: The aversion obtained was similar to that of the control group, which received saline $(P=0.466)$. The aversion indices of the rats in the 180 min group were lower than those of the rats that received the ani' injection at 15,40 , or $100 \mathrm{~min}$ $(P<0.001, P=0.001, P=0.001$, respectively).

\section{Strong taste input did not rescue the memory of a different strong taste input that was acquired when protein synthesis in the GC was halted}

We wanted to find out whether a strong taste input would stabilize memory formation with respect to a subsequent taste input that was administered under the influence of anisomycin in the GC. The facilitating taste was saccharin, and the potentiated taste, under the influence of anisomycin, was $\mathrm{NaCl}$. In order to achieve this objective we had to consider both the time frames we had identified in the previous experiments, with respect to the facilitation effect (Fig. 2) and to anisomycin sensitivity (Fig. 4). Three groups of rats were subjected to $\mathrm{LI}$ for $\mathrm{NaCl}$, following pre-exposure to $13 \mathrm{~mL}$ of $\mathrm{NaCl}$ on day 4 . We used $13 \mathrm{~mL}$ of $\mathrm{NaCl}$, since it is considered to be a strong taste input as defined in Figure 1, yet this amount of consumption allows for the later consumption of $10 \mathrm{~mL}$ of saccharin in the water-restricted rats. Two of the three groups were microinjected with anisomycin $60 \mathrm{~min}$ after the pre-exposure to $\mathrm{NaCl}$, i.e., within the time frame of sensitivity to anisomycin, according to the results presented in Figure 4B.

At 180 min prior to the anisomycin microinjection, i.e., outside the time frame of anisomycin efficacy (Fig. 4), the rats of the test group consumed $10 \mathrm{~mL}$ of saccharin (defined as a strong taste input, Fig. 1), whereas the control group consumed $10 \mathrm{~mL}$ of tap water. Our hypothesis was that a $10-\mathrm{mL}$ saccharin input would support memory formation with respect to the $13-\mathrm{mL} \mathrm{NaCl}$ pre-exposure that had been consumed under the influence of anisomycin. A third group served as control for the effect of anisomycin; rats in this group were microinjected with saline (a vehicle) $60 \mathrm{~min}$ after being preexposed to $13 \mathrm{~mL}$ of $\mathrm{NaCl}$, and they consumed $10 \mathrm{~mL}$ of tap water $180 \mathrm{~min}$ prior to the saline microinjection.

The results (Fig. 5B) demonstrate that, within this specific time frame, $10 \mathrm{~mL}$ of saccharin did not revive the memory formation with respect to the $13-\mathrm{mL} \mathrm{NaCl}$ pre-exposure that had been given under the influence of anisomycin. The experimental group (10 mL saccharin $\rightarrow 13 \mathrm{~mL} \mathrm{NaCl} \rightarrow$ anisomycin) did not show any detectable memory trace of the $\mathrm{NaCl}$ pre-exposure. The aversion elicited in this group was similar to that of the control group that consumed $10 \mathrm{~mL}$ of tap water (and not saccharin) 100 min before consumption of $13 \mathrm{~mL}$ of $\mathrm{NaCl}(P=0.649)$. Both "anisomycin" groups showed stronger aversion than that of the saline group $\left(P=6.24 \times 10^{-4}, P=3.29 \times 10^{-5}\right.$ among the ani' and the ani' + saccharin groups, respectively; ANOVA: $\left.F_{(2,20)}=22.057, P<0.001\right)$.

Levene's test for equality of variances between the two groups that received anisomycin revealed that the variance within the group that consumed saccharin 100 min before $\mathrm{NaCl}$ was lower than that within the group that consumed water at the same time point. The variances were $0.913 \times 10^{-3}$ and $4.359 \times 10^{-3}$, respectively $(F=4.774, P=0.046)$. 
A

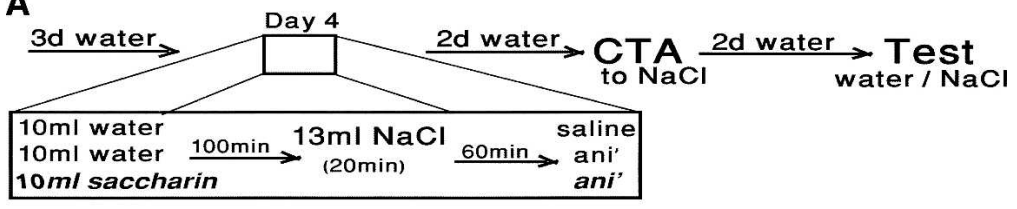

B

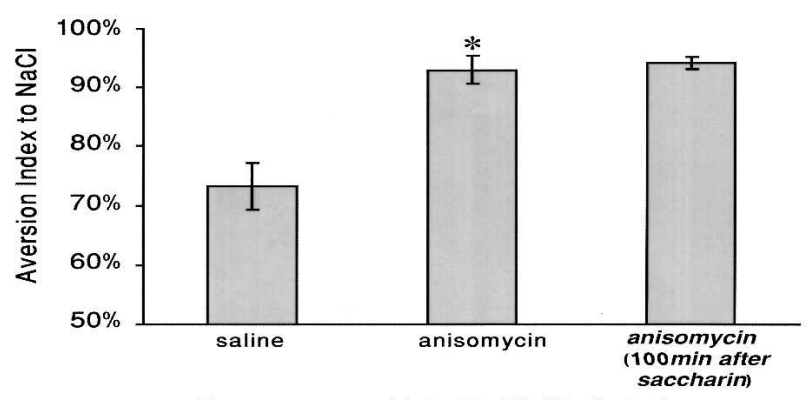

Pre exposure (LI) to $\mathrm{NaCl}, 60 \mathrm{~min}$ before...

* higher than the saline group

Figure 5. A saccharin input did not enhance memory formation with respect to an $\mathrm{NaCl}$ input given under the influence of anisomycin. (A) All the rats consumed $13 \mathrm{~mL}$ of $\mathrm{NaCl}$ under the $\mathrm{LI}$ paradigm, and $60 \mathrm{~min}$ after the pre-exposure, two groups of rats were administered anisomycin, injected bilaterally into the GC. At 180 min prior to the anisomycin injection those in the test group consumed $10 \mathrm{~mL}$ of saccharin and the control rats consumed $10 \mathrm{~mL}$ of tap water. Those in an additional control group were injected with saline 60 min after the consumption of $13 \mathrm{~mL}$ of NaCl , and later consumed $10 \mathrm{~mL}$ of tap water 180 min before the saline injection. (B) The aversion of the saccharin $\rightarrow \mathrm{NaCl} \rightarrow$ ani' group was not different from that of the water $\rightarrow \mathrm{NaCl} \rightarrow$ ani' group: The aversion indices were $94.16 \pm 1.0 \% n=9$ and $93.02 \pm 2.33 \% n=8$, respectively, $P=0.649$. Both groups showed stronger aversions than the saline group, which exhibited an index of $73.16 \pm 3.942 \% n=6$. The significance levels were $P=6.24 \times 10^{-4}$ and $P=3.29 \times 10^{-5}$ for comparison with the ani' and the ani' + saccharin groups, respectively. ANOVA: $F_{(2,20)}=22.057, P=0.0001$. The variance within the saccharin $\rightarrow \mathrm{NaCl} \rightarrow$ ani group was lower than that within the water $\rightarrow \mathrm{NaCl} \rightarrow$ ani' group: $0.913 \times 10^{-3}$ and $4.359 \times 10^{-3}$, respectively, $F=4.774, P=0.046$.

\section{Discussion}

The present study exploited the advantages and the special characteristics of taste learning - a learning/memory paradigm that enables highly quantified results to be obtained in a single trialand the well characterized neuroanatomy and biochemistry of the relevant cortical area during learning, consolidation, and retrieval (e.g., Rosenblum et al. 1997; Berman et al. 1998; Bures et al. 1998; Ferreira et al. 2002; Bermudez-Rattoni 2004). We used tastes that are highly soluble in water and that exhibit similar somatosensory quality dimensions (temperature and texture) but differing taste qualities. In addition, since taste learning is simple and takes place in the animal's home cage, there are very few parameters that impinge on the learning session itself (see Materials and Methods for further details). We aimed to study the ability of a strong taste input to facilitate the learning of a subsequently consumed, different weak input. Several studies have explored the functionality of unimodal interactions; they include: effects of priming in a word completion test within modality (Graf et al. 1985), disruption of memory formation by an immediately successive input from the same modality in motorskill learning in humans (Goedert and Willingham 2002), and effects of priming in visual displacement in monkeys (Flook and McGonigle 1977) and in taste learning in rats (Merhav et al. 2006).

We found that the facilitation of taste learning by a previous taste input was time-limited and that its magnitude was inversely correlated with the time interval between the two taste stimuli (Fig. 2). The wide time frame could be a result of the lingering nature of taste-learning processes. Protein expression in taste learning and interactions between inputs in taste conditioning and taste interference were characterized by prolonged time intervals (Davis and Bures 1972; Merhav et al. 2006).

In the present study, whereas a novel taste facilitated memory formation with respect to a different weak taste input, a familiar taste did not (Fig. 3). In addition, it is clear that the various biochemical alterations observed in the GC, in correlation with taste learning should be attributed to "novelty" and not to the taste input per se (Berman and Dudai 2001; Bahar et al. 2004). In a similar way, strong but not weak inputs are correlated with biochemical modifications in the GC (Belelovsky et al. 2005).

In recent years, many studied were guided be the hypothesis that long-term potentiation (LTP) shares molecular and cellular properties with learning. In the current work we took the opposite approach; we were inspired by recent studies of interaction between two inputs on the consolidation phase of LTP in the hippocampus (Frey and Morris 1997) and long-term facilitation (LTF) in the Aplysia (Martin et al. 1997) and have searched for similar phenomenon in taste learning.

Although the relations between LTP and learning processes are complex, it is clear that, in many cases, learning and LTP depend on similar molecular mechanisms (Izquierdo et al. 2006; Sigurdsson et al. 2007). One of the most prominent similarities between the two lies in the biochemical nature of molecular consolidation: It is dependent on functional protein synthesis machinery in the relevant circuit (Frey et al. 1988; Rosenblum et al. 1993; Meiri and Rosenblum 1998). In a similar way to the effect of novelty in potentiating weak taste memory, early LTP in the dentate gyrus of a freely moving rat was potentiated into L-LTP, following exploration of a new environment, but not of a familiar one (Straube et al. 2003a,b).

However, it is important to note that in contrast to LTP, in taste learning, "weak" does not mean early and "strong" does necessarily refer to long-term memory. The observation that three weak learning episodes ( $24 \mathrm{~h}$ apart) induced clear long-term taste memory suggests that in the case of taste learning weak input does induce long-term memory. Moreover, in light of our present observation of the taste facilitation phenomenon, we wanted to discover which memory stage was potentiated: acquisition or molecular consolidation. Since the molecular consolidation stage is characterized by sensitivity to protein-synthesis inhibition (Davis and Squire 1984), we tested the hypothesis that a strong novel taste input would rescue the memory of another strong taste that had been learned under the effect of inhibition of protein synthesis in the GC. The present results show that this was not the case, and that inhibition of protein synthesis did affect the memory of the second taste (Fig. 5). Therefore, we concluded that in the present study it was not the molecular consolidation phase that was affected by the previous strongtaste experience but, most probably, the acquisition stage. Moreover, one may suggest that the facilitation effect takes place at a location molecularly upstream of protein-synthesis regulation, e.g., a post-translation modification of existing proteins that underlies the acquisition process. A possible candidate for post- 
translation modification, which is known to take place in the CG several hours after novel taste learning, is tyrosine phosphorylation of the $2 \mathrm{~B}$ subunit of the NMDA receptor (Rosenblum et al. 1995, 1997).

This unimodal interaction not only did not facilitate the recollection of an input that was subject to protein-synthesis inhibition; it reduced the variance among animals. This result supports the hypothesis that taste memory would be deleted more effectively by protein-synthesis inhibitors in correlation with its magnitude at the time of acquisition. The paradoxical phenomenon, in which stronger inputs are better deleted than weaker ones by protein-synthesis inhibitors, was previously demonstrated in relation to taste and fear extinction (Eisenberg et al. 2003).

What might be the neurobiological process that underlies the facilitation effect we identified in taste learning in the present study? Since both first and second learning sessions mainly involved unimodal taste learning, we consider that the same brain loci subserved both tasks. Moreover, the GC, which resides within the insular cortex, is hypothesized to play a pivotal role in taste learning and, therefore, can be hypothesized to be the major site, in the brain, of interaction between the memory traces of the two tastes (e.g., Rosenblum et al. 1993). It is thus possible that the interaction between strong and weak taste inputs is mediated via a synergistic interplay of novelty-triggered long-term neuromodulatory activity, e.g., acetylcholine release, and weak stimulation, an interplay that promotes activity in the relevant circuit. A feasible molecular scenario, hypothesized to take place in the GC, is the following: The first strong taste input triggers a release of acetylcholine in a vast portion of the GC, which continues for many minutes (Naor and Dudai 1996; Miranda et al. 2000). The cortical release of acetylcholine can enhance tyrosine phosphorylation of the 2B subunit of the NMDA receptor (Rosenblum et al. 1996) and can maintain the NMDA receptors in a potentiated state for several hours, thereby facilitating the acquisition of another consecutive weak taste input.

\section{Materials and Methods}

\section{Subjects}

Adult Sprague Dawley male rats weighing 200 g, supplied by Harlan Laboratories, Jerusalem, were caged individually at $22 \pm 2^{\circ} \mathrm{C}$ on a $12 / 12$-h light/dark cycle, with water and laboratory rodent chow ad libitum, unless otherwise indicated. The procedure was performed in strict accordance with the University of Haifa regulations and with guidelines laid down by the US National Institutes of Health.

\section{Behavioral paradigms}

\section{Conditioned taste aversion (CTA)}

Saccharin at $0.1 \%$ or $\mathrm{NaCl}$ at $0.3 \%(\mathrm{w} / \mathrm{v}$, as sodium salt) were the novel tastes used as the conditioned stimulus (CS), and an i.p. injection of $0.15 \mathrm{M} \mathrm{LiCl}$ at $2 \%$ of body weight was used as the malaise-inducing agent, i.e., the unconditioned stimulus (UCS). The rats were trained for $3 \mathrm{~d}$ to drink their daily ration from two pipettes, each containing $10 \mathrm{~mL}$ of water, during a 20 -min period. Day 4 was the conditioning day, on which rats received 20 $\mathrm{mL}$ of taste and were injected with $\mathrm{LiCl} 60 \mathrm{~min}$ later. Control rats were injected with the same volume of saline. On days 5 and 6 the rats received water as on days 1-3. On day 7 a multiple-choice test was administered: The rats were offered six pipettes, of which three contained $5 \mathrm{~mL}$ of the conditioned taste and three contained $5 \mathrm{~mL}$ of water. The rats were allowed to drink for $20 \mathrm{~min}$, and the amount they consumed of each solution was measured. The aversion index was defined in terms of the volumes consumed in the test, as ([volume of water]/[volume of water + volume of taste]) $\times 100 ; 50 \%$ is the chance level, and the higher the aversion, the stronger the rat's preference for water over the conditioned taste.

\section{Latent inhibition (LI) to CTA}

The rats were trained for $3 \mathrm{~d}$ to drink their daily ration, as in the CTA test. Day 4 was the pre-exposure day, i.e., the day on which the LI was induced: The rats were given 5,10 , or $15 \mathrm{~mL}$ of the novel taste, followed after several hours by sufficient water to complete the daily liquid intake of $20 \mathrm{~mL}$. On days 5 and 6 the rats drank water, as on days $1-3$. On the seventh day, conditioning to the taste used in the pre-exposure was applied, as described for the CTA test. Three days later, conditioning aversion was tested by allowing the rats to choose between water and the taste, and was measured as in the CTA test.

\section{Pharmacology}

\section{Surgery}

The rats were anesthetized with Equithesin $\left(2.12 \%[\mathrm{w} / \mathrm{v}] \mathrm{MgSO}_{4}\right.$, $10 \%$ [v/v] ethanol, 39.1\% [v/v] 1,2-propranolol, $0.98 \%[\mathrm{w} / \mathrm{v}]$ sodium pentobarbital, and $4.2 \%$ [w/v] chloral hydrate) at $0.30 \mathrm{~mL}$ per $100 \mathrm{~g}$ body weight. They were then restrained in a stereotactic apparatus (Stoelting) and implanted bilaterally with $10 \pm 0.05$ $\mathrm{mm}, 23$-gauge, stainless-steel guide cannulae above the GCs. Coordinates, with reference to Bregma were: $\mathrm{A} / \mathrm{P}=+1.2 \mathrm{~mm}$, $\mathrm{L} / \mathrm{M}= \pm 5.5 \mathrm{~mm}, \mathrm{D} / \mathrm{V}=-5.5 \mathrm{~mm}$. The cannulae were fixed in position with acrylic dental cement and secured with two skull screws. A stylus was placed in each guide cannula to prevent clogging, and the animals were allowed $1 \mathrm{wk}$ to recover from surgery before undergoing the experimental manipulations.

\section{Drugs}

Anisomycin (Sigma) was dissolved in equimolar $5 \mathrm{~N} \mathrm{HCl}$, adjusted to $\mathrm{pH} 7-7.5$ by adding $5 \mathrm{~N} \mathrm{NaOH}$, and brought to a final concentration in saline of $100 \mu \mathrm{g} / \mu \mathrm{L}$.

\section{Microinjection}

The stylus was removed from the guide cannula, and a 28-gauge, 11-mm-long injection cannula, extending $1 \mathrm{~mm}$ from the tip of the guide cannula, was carefully inserted. The injection cannula was connected via PE20 tubing to a Hamilton micro-syringe, driven by a micro-injection pump (CMA/100; Carnegie Medicin) that operated at a rate of $1 \mu \mathrm{L} / \mathrm{min}$, for $1 \mathrm{~min}$. Following injection, the injection canulla was left in place for an additional 30 sec before withdrawal, to minimize dragging of injected liquid back along the injection track.

\section{Histology}

The brains were removed, frozen with dry ice, and kept at $-80^{\circ} \mathrm{C}$. Coronal $30-\mu \mathrm{m}$ sections were cut in a cryostat, stained with cresyl violet, and examined with a computerized Olympus camera. All the implanted animals were included in the statistical analysis (i.e., no animal was excluded after the histological analysis).

\section{Statistical analysis}

Differences between groups (multiple comparisons) were subjected to one-way ANOVA. For post hoc comparisons, an LSD contrast test was used, with an $\alpha$ level of 0.05. Differences between the variances of groups were subjected to Levene's test for equality of variances. Results are presented as means \pm SEM.

\section{Acknowledgments}

This work was supported by an ISF grant to K.R.

\section{References}

Bahar, A., Dudai, Y., and Ahissar, E. 2004. Neural signature of taste familiarity in the gustatory cortex of the freely behaving rat. $J$. Neurophysiol. 92: 3298-3308.

Balas, M., Roitenberg, N., Giladi, N., and Karni, A. 2007. When practice does not make perfect: Well-practiced handwriting interferes with the consolidation phase gains in learning a movement sequence. Exp. Brain Res. 178: 499-508.

Banko, J.L., Poulin, F., Hou, L., DeMaria, C.T., Sonenberg, N., and Klann, E. 2005. The translation repressor 4E-BP2 is critical for eIF4F 
complex formation, synaptic plasticity, and memory in the hippocampus. J. Neurosci. 25: 9581-9590.

Banko, J.L., Hou, L., Poulin, F., Sonenberg, N., and Klann, E. 2006. Regulation of eukaryotic initiation factor $4 \mathrm{E}$ by converging signaling pathways during metabotropic glutamate receptor-dependent long-term depression. J. Neurosci. 26: 2167-2173.

Belelovsky, K., Elkobi, A., Kaphzan, H., Nairn, A.C., and Rosenblum, K. 2005. A molecular switch for translational control in taste memory consolidation. Eur. J. Neurosci. 22: 2560-2568.

Berman, D.E. and Dudai, Y. 2001. Memory extinction, learning anew, and learning the new: Dissociations in the molecular machinery of learning in cortex. Science 291: 2417-2419.

Berman, D.E., Hazvi, S., Rosenblum, K., Seger, R., and Dudai, Y. 1998. Specific and differential activation of mitogen-activated protein kinase cascades by unfamiliar taste in the insular cortex of the behaving rat. J. Neurosci. 18: 10037-10044.

Bermúdez-Rattoni, F. 2004. Molecular mechanisms of taste-recognition memory. Nat. Rev. Neurosci. 5: 209-217.

Bures, Y., Bermudez-Rattoni, F., and Yamamoto, T. 1998. Conditioned taste aversion. Oxford Medical Publications, Oxford, UK.

Costa-Mattioli, M., Gobert, D., Stern, E., Gamache, K., Colina, R., Cuello, C., Sossin, W., Kaufman, R., Pelletier, J., Rosenblum, K., et al. 2007. eIF $2 \alpha$ phosphorylation bidirectionally regulates the switch from short to long-term synaptic plasticity and memory. Cell 129: $195-206$.

Davis, J.L. and Bures, J. 1972. Disruption of saccharin-aversion learning in rats by cortical spreading depression in the CS-US interval. $J$. Comp. Physiol. Psychol. 80: 398-402.

Davis, H.P. and Squire, L.R. 1984. Protein synthesis and memory: A review. Psychol. Bull. 96: 518-559.

De la Casa, L.G. and Lubow, R.E. 2002. An empirical analysis of the super-latent inhibition effect. Anim. Learn. Behav. 30: 112-120.

Dudai, Y. 2004. The neurobiology of consolidations, or, how stable is the engram? Annu. Rev. Psychol. 55: 51-86.

Eisenberg, M., Kobilo, T., Berman, D.E., and Dudai, Y. 2003. Stability of retrieved memory: Inverse correlation with trace dominance. Science 301: $1102-1104$

Ferreira, G., Gutierrez, R., De La Cruz, V., and Bermudez-Rattoni, F. 2002. Differential involvement of cortical muscarinic and NMDA receptors in short- and long-term taste aversion memory. Eur. J. Neurosci. 16: 1139-1145.

Flook, J.P. and McGonigle, B.O. 1977. Serial adaptation to conflicting prismatic rearrangement effects in monkey and man. Perception 6: $15-29$.

Frey, U. and Morris, R.G. 1997. Synaptic tagging and long-term potentiation. Nature 385: $533-536$.

Frey, U., Krug, M., Reymann, K.G., and Matthies, H. 1988. Anisomycin, an inhibitor of protein synthesis, blocks late phases of LTP phenomena in the hippocampal CA1 region in vitro. Brain Res. 452: $57-65$.

Gallo, M., Bielavska, E., Roldan, G., and Bures, J. 1998. Tetrodotoxin inactivation of the gustatory cortex disrupts the effect of the $\mathrm{N}$-methyl-D-aspartate antagonist ketamine on latent inhibition of conditioned taste aversion in rats. Neurosci. Lett. 240: 61-64.

Goedert, K.M. and Willingham, D.B. 2002. Patterns of interference in sequence learning and prism adaptation inconsistent with the consolidation hypothesis. Learn. Mem. 9: 279-292.

Graf, P., Shimamura, A.P., and Squire, L.R. 1985. Priming across modalities and priming across category levels: Extending the domain of preserved function in amnesia. J. Exp. Psychol. Learn. Mem. Cogn. 11: $386-396$.
Houpt, T.A. and Berlin, R. 1999. Rapid, labile, and protein synthesisindependent short-term memory in conditioned taste aversion. Learn. Mem. 6: $37-46$

Izquierdo, I., Bevilaqua, L.R., Rossato, J.I., Bonini, J.S., Medina, J.H., and Cammarota, M. 2006. Different molecular cascades in different sites of the brain control memory consolidation. Trends Neurosci. 29: $496-505$.

Martin, K.C., Casadio, A., Zhu, H., Yaping, E., Rose, J.C., Chen, M., Bailey, C.H., and Kandel, E.R. 1997. Synapse-specific, long-term facilitation of aplysia sensory to motor synapses: A function for local protein synthesis in memory storage. Cell 91: 927-938.

Meiri, N. and Rosenblum, K. 1998. Lateral ventricle injection of the protein synthesis inhibitor anisomycin impairs long-term memory in a spatial memory task. Brain Res. 789: 48-55.

Merhav, M., Kuulmann-Vander, S., Elkobi, A., Jacobson-Pick, S., Karni, A., and Rosenblum, K. 2006. Behavioral interference and C/EBP $\beta$ expression in the insular-cortex reveal a prolonged time period for taste memory consolidation. Learn. Mem. 13: 571-574.

Miranda, M.I., Ramirez-Lugo, L., and Bermudez-Rattoni, F. 2000. Cortical cholinergic activity is related to the novelty of the stimulus. Brain Res. 882: 230-235.

Naor, C. and Dudai, Y. 1996. Transient impairment of cholinergic function in the rat insular cortex disrupts the encoding of taste in conditioned taste aversion. Behav. Brain Res. 79: 61-67.

Revusky, S.H. and Bedarf, E.W. 1967. Association of illness with prior ingestion of novel foods. Science 155: 219-220.

Rosenblum, K., Meiri, N., and Dudai, Y. 1993. Taste memory: The role of protein synthesis in gustatory cortex. Behav. Neural Biol. 59: $49-56$.

Rosenblum, K., Schul, R., Meiri, N., Hadari, Y.R., Zick, Y., and Dudai, Y. 1995. Modulation of protein tyrosine phosphorylation in rat insular cortex after conditioned taste aversion training. Proc. Natl. Acad. Sci. 92: $1157-1161$.

Rosenblum, K., Dudai, Y., and Richter-Levine, G. 1996. LTP increases tyrosine phosphorylation of the N-methyl-D-aspartate receptor in the rat dentate gyrus in vivo. Proc. Natl. Acad. Sci. 93: 10457-10460.

Rosenblum, K., Berman, D., Hazvi, S., and Dudai, Y. 1997. NMDA receptor and the tyrosine phsophorylation of its $2 \mathrm{~B}$ subunit in taste learning in the rat insular cortex. J. Neurosci. 17: 5129-5135.

Seidler, R.D. 2007. Aging affects motor learning but not savings at transfer of learning. Learn. Mem. 14: 17-21.

Sigurdsson, T., Doyere, V., Cain, C.K., and Ledoux, J.E. 2007. Long-term potentiation in the amygdala: A cellular mechanism of fear learning and memory. Neuropharmacology 52: 215-227.

Straube, T., Korz, V., and Frey, J.U. 2003a. Bidirectional modulation of long-term potentiation by novelty-exploration in rat dentate gyrus. Neurosci. Lett. 344: 5-8.

Straube, T., Korz, V., Balschun, D., and Frey, J.U. 2003b. Requirement of beta-adrenergic receptor activation and protein synthesis for LTP-reinforcement by novelty in rat dentate gyrus. J. Physiol. 552: 953-960

Yefet, K., Merhav, M., Kuulmann-Vander, S., Elkobi, A., Belelovsky, K., Jacobson-Pick, S., Meiri, N., and Rosenblum, K. 2006. Different signal transduction cascades are activated simultaneously in the rat insular cortex and hippocampus following novel taste learning. Eur. J. Neurosci. 24: 1434-1442.

Received February 28, 2008; accepted in revised form March 31, 2008. 


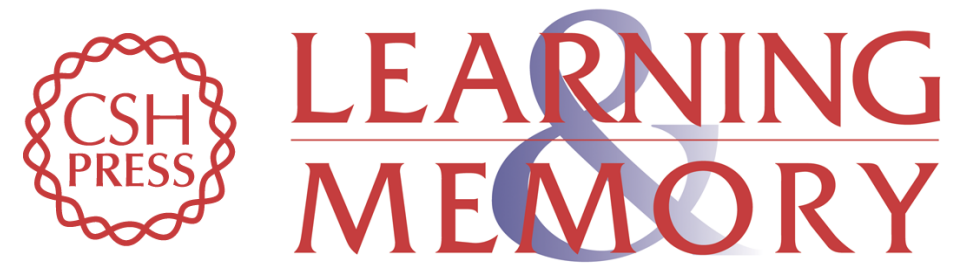

\section{Facilitation of taste memory acquisition by experiencing previous novel taste is protein-synthesis dependent}

Maayan Merhav and Kobi Rosenblum

Learn. Mem. 2008, 15:

Access the most recent version at doi:10.1101//m.986008

References This article cites 38 articles, 13 of which can be accessed free at: http://learnmem.cshlp.org/content/15/7/501.full.html\#ref-list-1

License

Email Alerting

Receive free email alerts when new articles cite this article - sign up in the box at the Service top right corner of the article or click here. 